\title{
Deficiency of Nrf2 Accelerates the Effector Phase of Arthritis and Aggravates Joint Disease
}

\author{
Nuria Maicas,' María Luisa Ferrándiz, Rita Brines,' Lidia Ibáñez, Antonio Cuadrado,2 \\ Marije I. Koenders, ${ }^{3}$ Wim B. van den Berg, ${ }^{3}$ and Maria José Alcaraz ${ }^{1}$
}

\begin{abstract}
Aims: Although oxidative stress participates in the etiopathogenesis of rheumatoid arthritis, its importance in this inflammatory disease has not been fully elucidated. In this study, we analyzed the relevance of the transcription factor Nrf2, master regulator of redox homeostasis, in the effector phase of an animal model of rheumatoid arthritis, using the transfer of serum from $\mathrm{K} / \mathrm{BxN}$ transgenic mice to $\mathrm{Nrf2}^{-/-}$mice. Results: Nrf2 deficiency accelerated the incidence of arthritis, and animals showed a widespread disease affecting both front and hind paws. Therefore, the inflammatory response was enhanced, with increased migration of leukocytes and joint destruction in front paws. We observed an increased production of tumor necrosis factor- $\alpha$, interleukin- 6 , and CXCL-1 in the joint, with small changes in eicosanoid levels. Serum levels of CXCL-1 and receptor activator for nuclear factor $\kappa \mathrm{B}$ ligand were enhanced and osteocalcin decreased in arthritic $\mathrm{Nrf2}^{-/-}$mice. The expression of cyclooxygenase-2, inducible nitric oxide synthase, and peroxynitrite in the joints was higher in Nrf2 deficiency, whereas heme oxygenase-1 was downregulated. Innovation: Nrf2 may be a therapeutic target for arthritis. Conclusion: Our results support a protective role of Nrf2 against joint inflammation and degeneration in arthritis. Antioxid. Redox Signal. 15, 889-901.
\end{abstract}

\section{Introduction}

$\mathbf{T}$ HE TRANSCRIPTION FACTOR NRF2 (NF-E 2 -related factor 2) controls the expression of cytoprotective genes involved in electrophile conjugation $(31,34)$. Although Nrf2 is dispensable for mouse development (4), this transcription factor regulates an antioxidant defense system and its deficiency leads to augmented oxidative stress and cytokine production (47). Nrf2 may protect against chemical carcinogenesis (2) and cancer metastasis by the regulation of the immunological response (41). On the contrary, the presence of high constitutive Nrf2 levels in some tumor cells increases resistance to cancer therapy (53). Other biological roles have been proposed for this transcription factor, such as the control of adipocyte differentiation (37), the modulation of hepatic lipid homeostasis (16), or the promotion of atherogenesis (44).

Several lines of evidence have demonstrated that a defective Nrf2 activity results in greater sensitivity to oxidative and inflammatory disorders such as asthma, pulmonary fibrosis, neurodegeneration, colitis, and sepsis $(8,18,23,38,40,45)$. In addition, Nrf2 deficiency results in a higher sensitivity to inflammatory responses induced by bacteria or lipopolysac- charide. Thus, macrophages from $\mathrm{Nrf2}^{-/-}$mice generate 2-fold higher reactive oxygen species levels after lipopolysaccharide stimulation compared with cells from wild-type animals (25). In particular, the enhanced production of reactive oxygen species by NADPH oxidase could mediate the inflammatory response induced by toll-like receptor 4 activation in $\mathrm{Nrf2}^{-/}$

\section{Innovation}

It has been accepted that activation of Nrf2 results in anti-inflammatory effects in different biological systems. In contrast, knowledge on the role of this transcription factor in rheumatoid arthritis is scarce. We have shown in the K/ BxN serum transfer model that Nrf2 deficiency results in a widespread disease with higher production of relevant mediators such as reactive oxygen and nitrogen species, cytokines and chemokines, enhanced migration of inflammatory cells, cartilage degradation, and bone erosion. Therefore, Nrf2 may counteract important processes in the effector phase of arthritis to protect joint structures. Our findings thus support that Nrf2 may be a therapeutic target for arthritis.

\footnotetext{
${ }^{1}$ Department of Pharmacology, University of Valencia, Valencia, Spain.

${ }^{2}$ Centro de Investigación en Red sobre Enfermedades Neurodegenerativas (CIBERNED). Department of Biochemistry and Alberto Sols Biomedical Research Institute UAM-CSIC, Faculty of Medicine, Autonomous University of Madrid, Madrid, Spain.

${ }^{3}$ Rheumatology Research and Advanced Therapeutics, Radboud University Nijmegen, Nijmegen, The Netherlands.
} 
mice (25). Similarly, deficiency in Nrf2 increases the inflammation involved in secondary brain injury after traumatic lesions (21) and leads to induction of angiogenic factors and promotion of ischemia-induced neovascularization (17).

Despite the established antioxidant and anti-inflammatory role of Nrf2, little is known about the involvement of this transcription factor in arthritis. Previous studies have suggested that Nrf2 may participate in the regulation of the immune response (27) and chondrocyte integrity (13). Recently, it has been shown that Nrf2 expression is upregulated in rheumatoid arthritis synoviocytes compared with healthy donors, and the deficiency in this transcription factor leads to increased joint damage in anti-collagen II antibody-induced arthritis (50). It has also been demonstrated that activation of Nrf2 and induction of heme oxygenase- 1 mediate the antiinflammatory and protective effects of cilostazol (35) and antirheumatic gold compounds (22). These findings highlight Nrf2 as a novel molecular target for arthritic diseases (24). In direct contrast, it has been reported that increased expression of Nrf2 in a subset of rheumatoid arthritis patients could lead to a more severe disease state (46). In addition, Nrf2 may play complex roles in articular cells as this transcription factor mediates the expression of antioxidant genes but negatively regulates chondrocyte and osteoblast differentiation $(14,15)$. Therefore, the role of Nrf2 in arthritis remains unclear.

This study was conducted to investigate the involvement of Nrf2 in the effector phase of arthritis. We sought to charac- terize the consequences of Nrf2 deficiency on key aspects of the inflammatory response and joint lesion to gain new insights into the underlying mechanisms of action. To address this question, we used an animal model that exhibits important features of human rheumatoid arthritis, the $\mathrm{K} / \mathrm{BxN}$ serum transfer model (49).

\section{Results}

\section{Evolution of arthritis}

In our experimental conditions, administration of serum from $\mathrm{K} / \mathrm{BxN}$ transgenic mice causes severe arthritis affecting mainly hind paw joints. We have followed the progression of arthritis in wild-type and $\mathrm{Nrf}^{-/-}$mice. Figures $1 \mathrm{~A}$ and $1 \mathrm{~B}$ show the time-course of arthritis incidence (as percentage of arthritic animals) and the arthritic score, as well as representative pictures of paws. In wild-type mice, maximal incidence of disease was reached on day 7 (hind paws) and 10 (front paws). Interestingly, maximal incidence appeared earlier in $\mathrm{Nrf}^{-/-}$mice (day 4 in hind paws and day 7 in front paws). A higher incidence of arthritis was observed in these animals from days 2 to 6 in hind paws and from days 4 to 8 in front paws, as compared with wild-type animals. As expected, arthritic score values were lower in front paws of wild-type mice compared with hind paws of the same group. In accordance with the high inflammatory response present in hind paws, $\mathrm{Nrf}^{-/-}$and wild-type mice showed similar score values
A
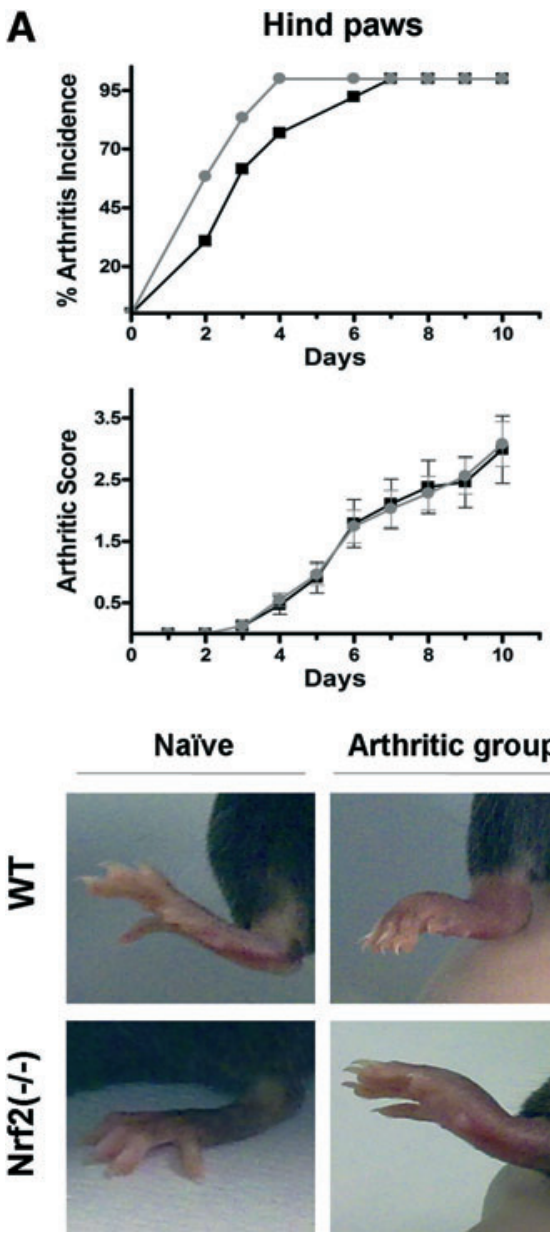

Arthritic group
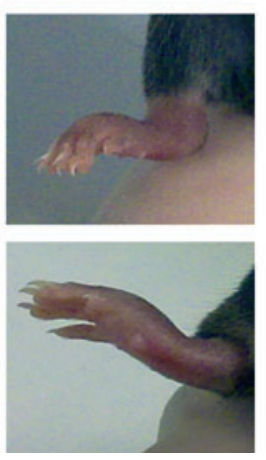

B
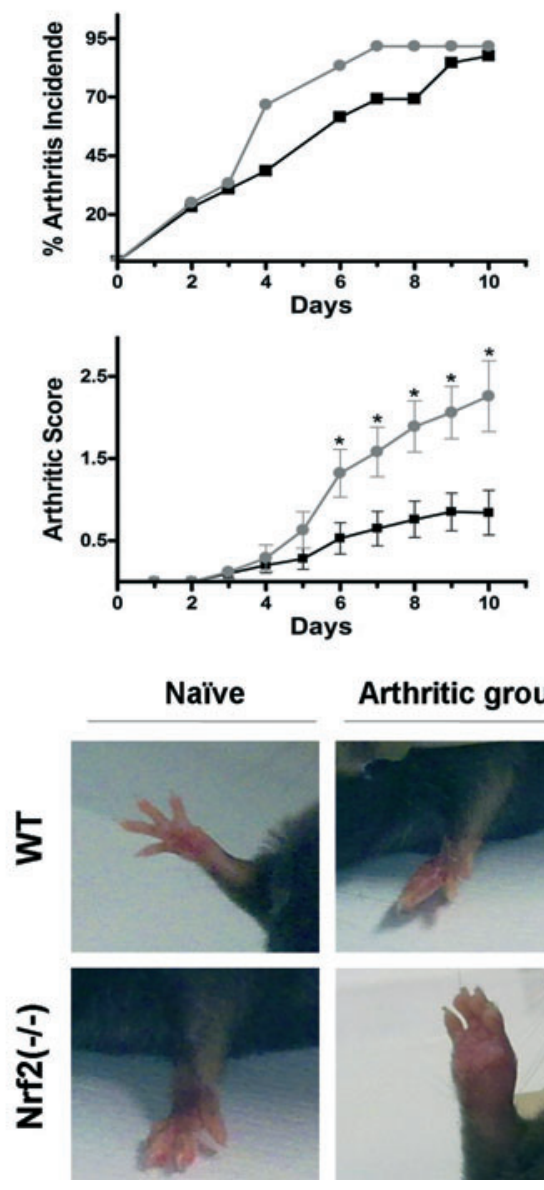

Arthritic group
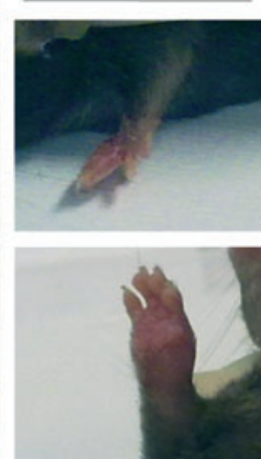

FIG. 1. Time-course of arthritis. (A) arthritis incidence (\%) and clinical score (mean \pm S.E.M) of hind paws $(n=8$ animals per group); $\mathrm{Nrf}^{-/-}$mice (circles), wildtype mice (squares). Pictures of representative hind paws taken at the end of the experiment (day 10). (B) arthritis incidence (\%) and clinical score (mean \pm S.E.M) of front paws $(n=8$ animals per group); $\mathrm{Nrf} 2^{-/-}$mice (circles), wildtype mice (squares); * $p<0.05$ compared to arthritic wild-type mice. Pictures of representative front paws taken at the end of the experiment (day 10). (To see this illustration in color, the reader is referred to the web version of this article at www.liebertonline.com/ ars). 
A

FIG. 2. Histological analysis of frontal sections of ankle joints on day 10. (A) A-H, safranin $\mathrm{O}$ and fast greenstained sections; I-P, hematoxylin and eosin-stained sections. A, E, I, M, ankle joint of naïve wild-type mouse; $\mathbf{B}$, $\mathbf{F}, \mathbf{J}, \mathbf{N}$, ankle joint of naïve $\mathrm{Nrf2}^{-/-}$mouse; C, G, K, O, ankle joint of arthritic wildtype mouse; $\mathbf{D}, \mathbf{H}, \mathbf{L}, \mathbf{P}$, ankle joint of arthritic $\mathrm{Nrf}^{-/-}$mouse. $\mathrm{C}$, cartilage; CA, calcaneous; JS, joint space; $S$, synovium; $T$, tibia. Original magnification X40 (A-D). Original magnification X100 (I-L). Original magnification X200 (E-H, M-P). (B) Histological score. Data represent mean \pm S.E.M. $(n=8$ animals per arthritic group and 4 for naïve group); ${ }_{* * *} p<0.001,{ }^{* *} p<0.01,{ }^{*} p<0.05$, each arthritic group compared to its respective naïve group. (To see this illustration in color, the reader is referred to the web version of this article at www.liebertonline.com/ars).

B
$4 x$
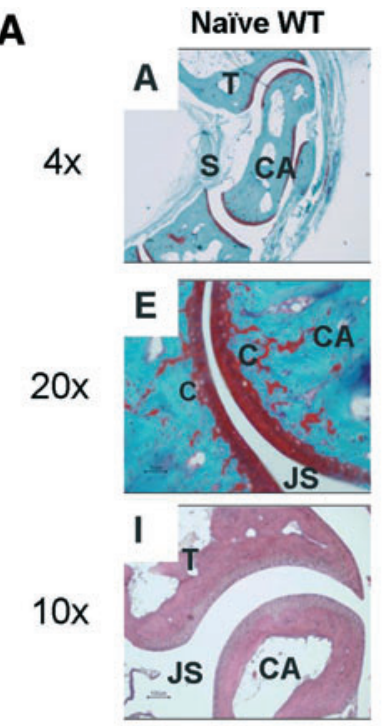

$20 x$

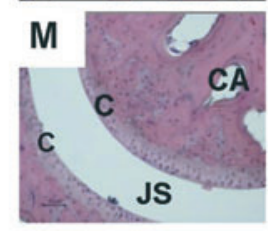

B
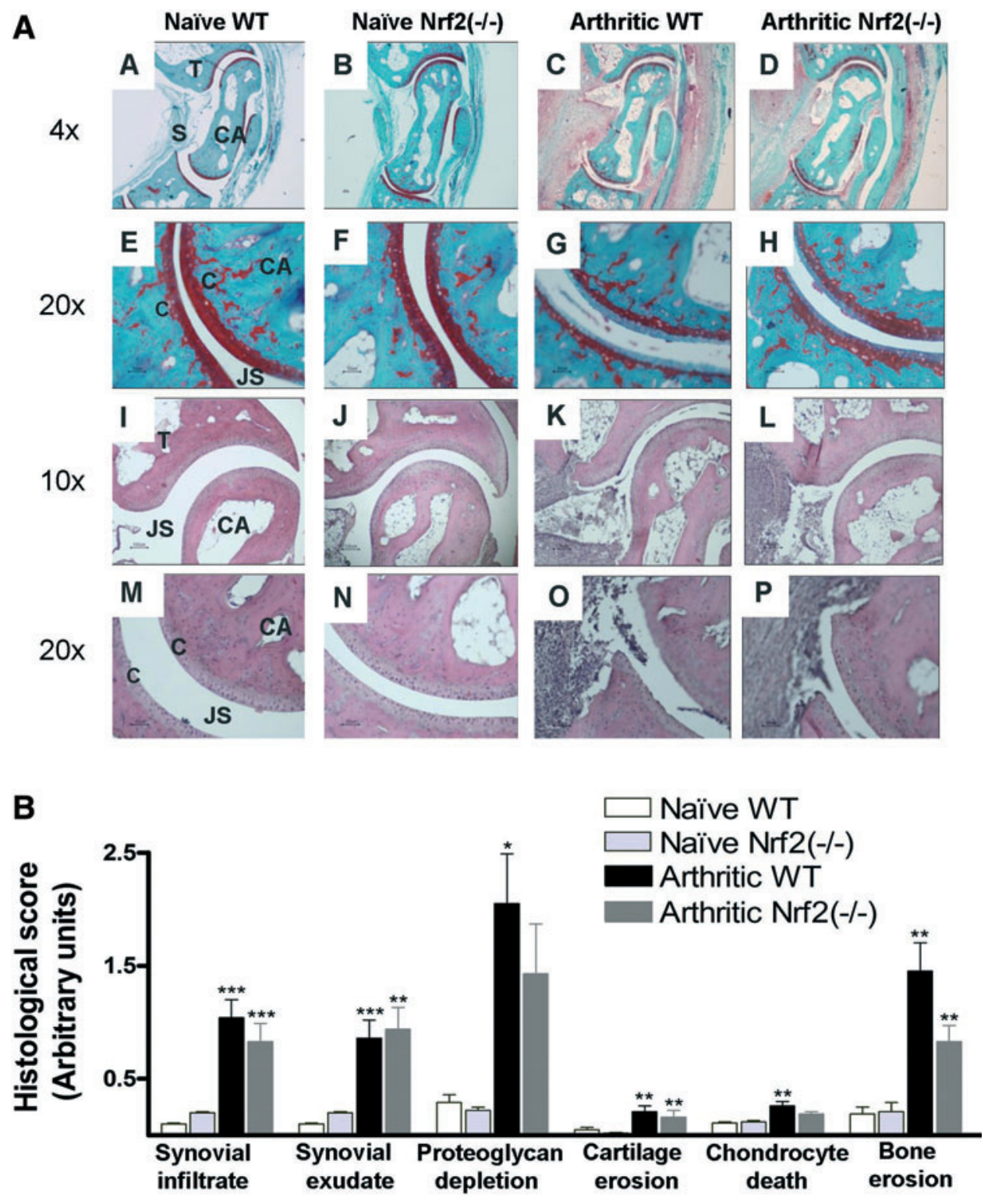

in both groups. In contrast, Nrf2 deficiency significantly enhanced the arthritic score of front paws from days 6 to 10 .

\section{Histological analysis of joint sections}

In line with the results obtained for the macroscopic arthritic score, the histological analysis of ankles on day 10 (Figs. 2A and 2B) revealed important inflammatory and erosive changes with the presence of synovial infiltrate and exudate, depletion of proteoglycan and bone erosion in both $\mathrm{Nrf}^{-/-}$and wild-type arthritic animals without significant statistical differences between both groups.

The histological analysis of front joint sections at the end of the experiment (day 10) (Figs. 3A, 3B, and 3C) indicated very little change in the arthritic wild-type group compared with its naïve control. In contrast, the arthritic process was intense in $\mathrm{Nrf}^{-/-}$mice and therefore we observed a marked infiltration of inflammatory cells into joint tissues as well as the presence of inflammatory exudate in the joint space. We also observed in these animals significant increases in proteoglycan deple-

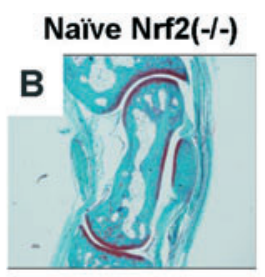

tion and bone erosion in comparison with arthritic wild-type mice.

\section{Levels of inflammatory mediators in serum}

As shown in Table 1, no significant differences were observed between naïve $\mathrm{Nrf}^{-}{ }^{-}$mice and their wild-type counterparts in constitutive levels of inflammatory mediators on day 10. The arthritic process in wild-type animals was accompanied by significant increases in serum IL-6, $\mathrm{PGD}_{2}$, 6ketoPGF ${ }_{1 \alpha}$ and $\mathrm{LTB}_{4}$, whereas in $\mathrm{Nrf}^{-/-}$mice besides these mediators CXCL-1, RANKL, and $\mathrm{PGE}_{2}$ were significantly enhanced with respect to naïve animals and osteocalcin decreased. In arthritic animals, Nrf2 deficiency increased CXCL1 and reduced 6-ketoPGF ${ }_{1 \alpha}, \mathrm{LTB}_{4}$, and osteocalcin.

\section{Levels of inflammatory mediators in paw homogenates}

In knee homogenates of day 10 (Fig. 4), we observed increases in IL- $1 \beta, \mathrm{CXCL}-1, \mathrm{PGE}_{2}, \mathrm{PGD}_{2}$, and $\mathrm{TXB}_{2}$ after the induction of arthritis in wild-type mice. Interestingly, the arthritic process in 
A
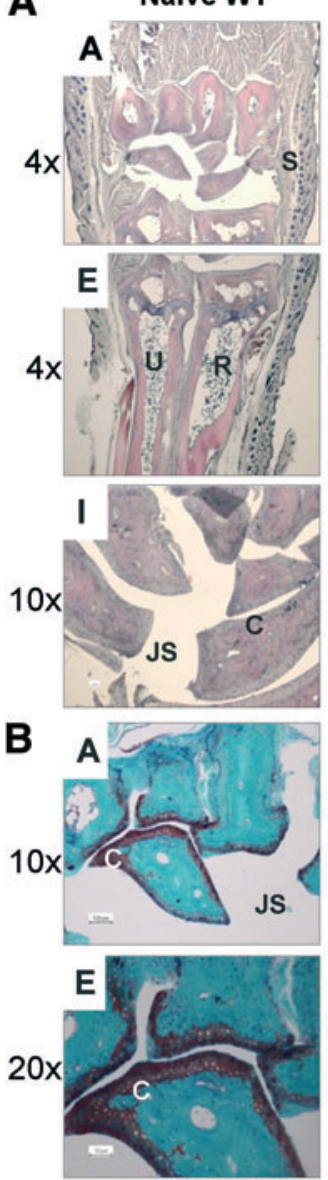

Naîve Nrf2 (-I-)
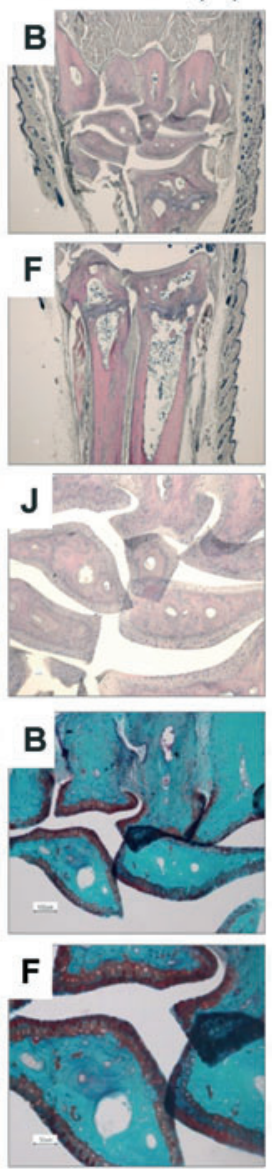

Arthritic WT
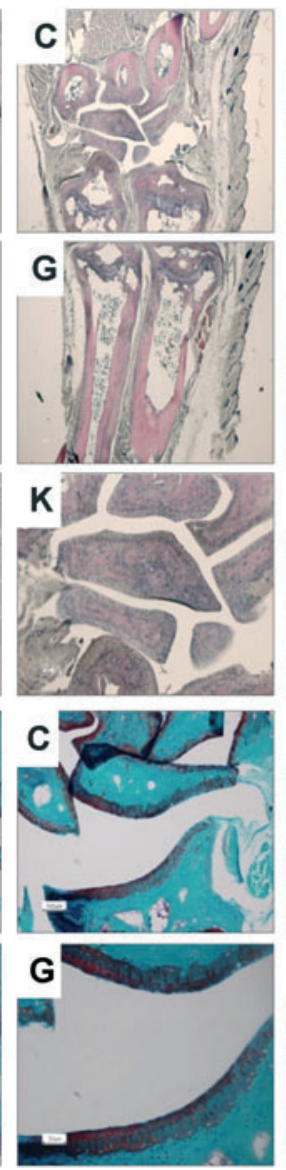

Arthritic Nrf2 (-I-)
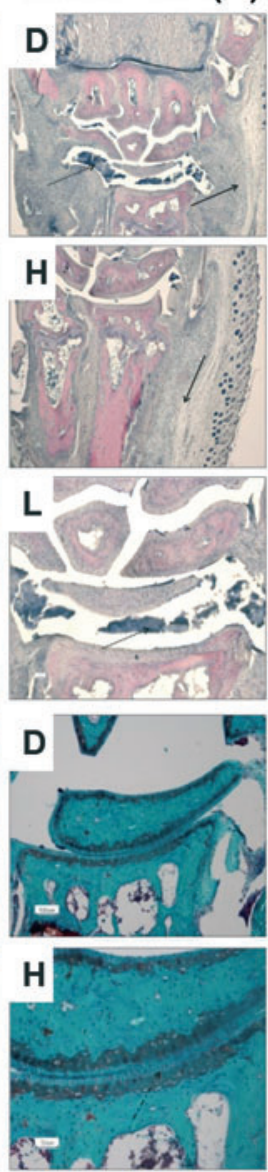
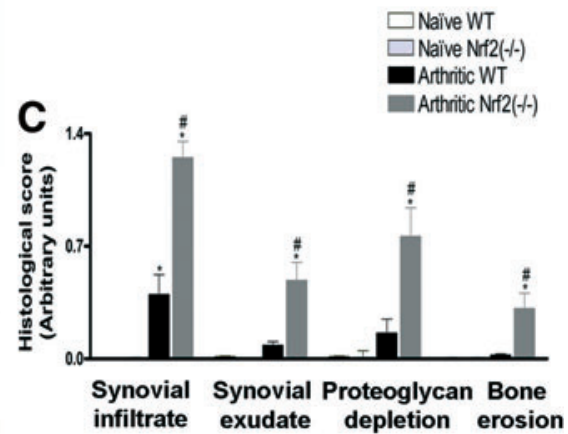

FIG. 3. Histological analysis of frontal sections of front joints on day 10. (A) Hematoxylin and eosin-stained sections. A, E, I, front joint of naïve wild-type mouse; B, F, J, front joint of naïve Nrf2 ${ }^{-/-}$mouse; C, G, K, front joint of arthritic wild-type mouse; D, H, L, front joint of arthritic Nrf2 $2^{-/-}$mouse. C, cartilage; JS, joint space; R, radius; S, synovium; U, ulna. The solid arrows indicate areas of cell infiltration. Broken arrows (...) indicate exudate. Original magnification X40 (A-H); original magnification X100 (I-L). (B) Safranin O and fast green-stained sections. A, E, front joint of naïve wild-type mouse; B, F, front joint of naïve $\mathrm{Nrf2}^{-}$mouse; C, G, front joint of arthritic wild-type mouse; D, H, front joint of arthritic Nrf2 ${ }^{-/-}$mouse. $\mathbf{C}$, cartilage; JS, joint space. Broken arrow indicates proteoglycan depletion from cartilage matrix (-). Original magnification $\times 100\left(\right.$ A-D). Original magnification X200 (E-H). (C) Histological score. Data represent mean \pm S.E.M, $n=4 ;{ }^{*} p<0.05$ each arthritic group compared with its respective naïve group, ${ }^{\#} p<0.05$ arthritic Nrf2 ${ }^{-}$- group with respect to arthritic wild-type group. (To see this illustration in color, the reader is referred to the web version of this article at www.liebertonline.com/ars).

the presence of Nrf2 deficiency led to the upregulation of all the inflammatory mediators assayed. In addition, the comparison of this group with arthritic wild-type animals showed significant increases in TNF- $\alpha$, IL- 6 , and CXCL- 1 . The levels of myeloper- oxidase activity, a marker of neutrophils, were also determined in knee homogenates. No significant differences were observed between naïve wild-type animals and naïve $\mathrm{Nrf2}^{-/-}$mice $(6982.3 \pm 2400.7$ and $5711.9 \pm 890.9$ Units/g joint, respectively,

Table 1. Levels of Inflammatory Mediators in Serum on Day 10

\begin{tabular}{lcccc}
\hline & Nä̈ve WT & Nä̈ve Nrf2 & Arthritic WT & Arthritic Nrf2 \\
\hline TNF- $\alpha(\mathrm{pg} / \mathrm{ml})$ & $3.58 \pm 0.10$ & $2.86 \pm 0.46$ & $4.17 \pm 0.51$ & $4.39 \pm 0.37$ \\
IL-6 $(\mathrm{pg} / \mathrm{ml})$ & $3.53 \pm 0.00$ & $3.25 \pm 0.86$ & $120.6 \pm 18.30^{* *}$ & $193.7 \pm 54.20^{* *}$ \\
CXCL-1 $(\mathrm{pg} / \mathrm{ml})$ & $20.56 \pm 0.78$ & $20.52 \pm 0.76$ & $33.13 \pm 4.29$ & $52.57 \pm 6.38^{* * \#}$ \\
Osteocalcin $(\mathrm{ng} / \mathrm{ml})$ & $197.97 \pm 25.16$ & $189.47 \pm 8.41$ & $141.51 \pm 10.09^{*}$ & $98.92 \pm 10.86^{* \#}$ \\
RANKL $(\mathrm{pg} / \mathrm{ml})$ & $118.1 \pm 16.58$ & $77.95 \pm 5.55$ & $144.6 \pm 20.55$ & $125.6 \pm 9.73^{*}$ \\
PGE 2 (ng/ml) & $2.93 \pm 0.46$ & $1.29 \pm 0.40$ & $3.75 \pm 0.43$ & $3.78 \pm 0.34^{*}$ \\
PGD $_{2}(\mathrm{ng} / \mathrm{ml})$ & $326.5 \pm 26.88$ & $215.2 \pm 35.01$ & $775.3 \pm 74.60^{*}$ & $1125 \pm 137.6^{*}$ \\
6-ketoPGF $_{1 \alpha}(\mathrm{ng} / \mathrm{ml})$ & $0.44 \pm 0.08$ & $0.51 \pm 0.13$ & $1.39 \pm 0.15^{*}$ & $0.99 \pm 0.08^{* \#}$ \\
LTB $_{4}(\mathrm{ng} / \mathrm{ml})$ & $27.36 \pm 2.49$ & $25.15 \pm 0.6$ & $37.21 \pm 1.12^{* *}$ & $29.69 \pm 1.30^{* \# \#}$ \\
\hline
\end{tabular}

WT (wild-type mice). Values are mean \pm S.E.M $(n=4-8) ;{ }^{* *} p<0.01,{ }^{*} p<0.05$ each arthritic group compared with its respective naïve group, $\# p<0.01, \# p<0.05$ arthritic Nrf2 ${ }^{-/-}$mice with respect to arthritic wild-type animals. Mann-Whitney U-test (two-tailed). 

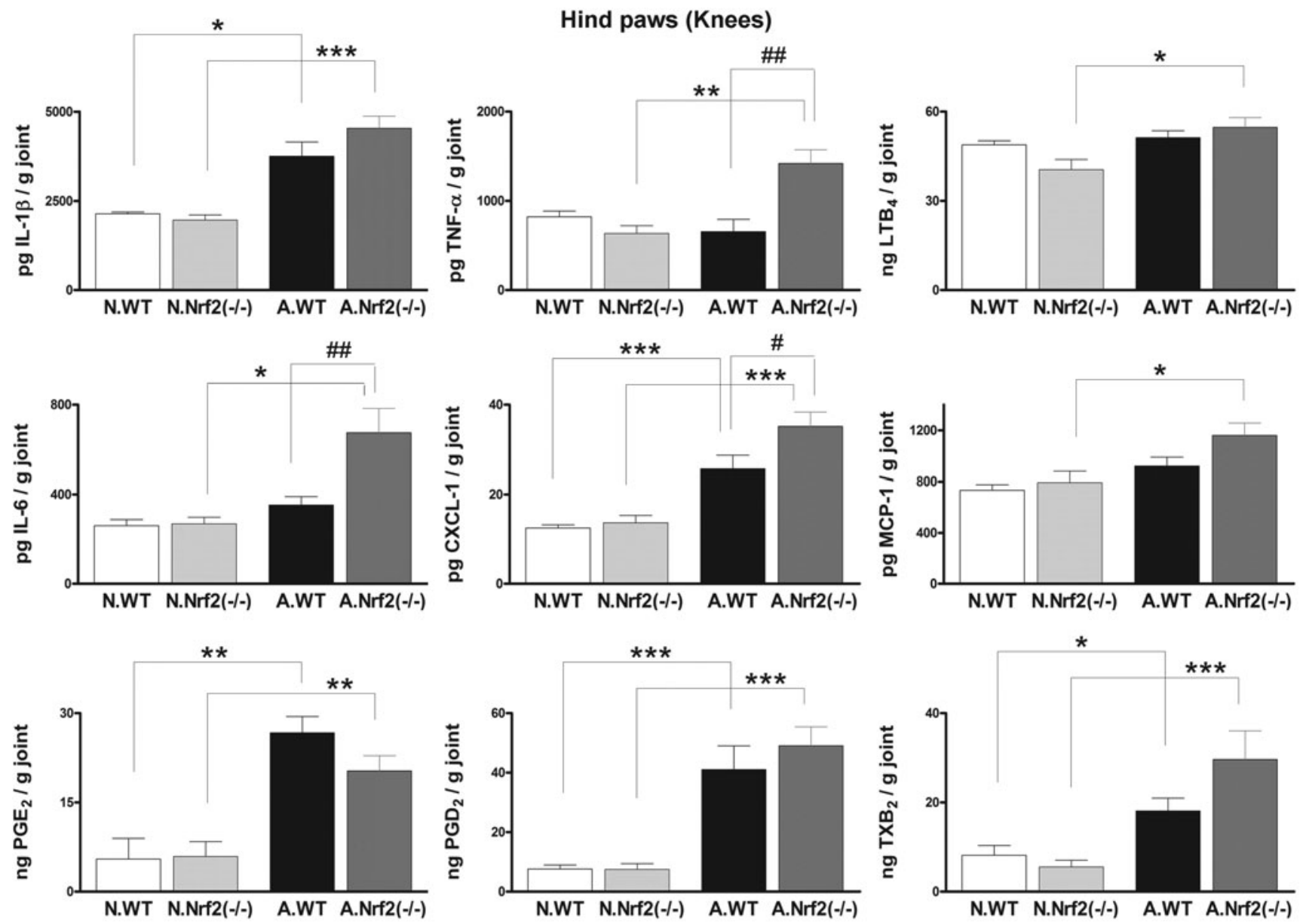

FIG. 4. Levels of inflammatory mediators in hind paw (knees) homogenates on day 10. Data represent mean \pm S.E.M, $n=4-8 ;{ }^{* * *} p<0.001,{ }^{* *} p<0.01,{ }^{*} p<0.05$ each arthritic group compared with its respective naïve group, ${ }^{\# \#} p<0.01,{ }^{\#} p<0.05$ arthritic $\mathrm{Nrf}^{-/-}$group with respect to arthritic wild-type group.

$n=4)$. The induction of arthritis resulted in a significant increase $(p<0.01)$ in myeloperoxidase activity with respect to the corresponding naïve animals $(23229.3 \pm 2048.0$ and $22582.7 \pm 2237.0$ Units/g joint, $n=8$, in arthritic wild-type and arthritic Nrf2deficient mice, respectively).

Figure 5 shows that the arthritic process in front paws increased IL- $1 \beta, \mathrm{LTB}_{4}, \mathrm{PGE}_{2}, \mathrm{PGD}_{2}$, and $\mathrm{TXB}_{2}$ in wild-type animals on day 10 , whereas in $\mathrm{Nrf} 2^{-/-}$mice, the levels of IL- $1 \beta$, TNF- $\alpha$, CXCL-1, PGE $2, \mathrm{PGD}_{2}$, and $\mathrm{TXB}_{2}$ were significantly enhanced. The induction of arthritis in $\mathrm{Nrf}^{-/-}$mice resulted in higher TNF- $\alpha$ and lower $\mathrm{LTB}_{4}$ levels compared with arthritic wild-type animals.

In front paws, increased myeloperoxidase activity was observed in naïve Nrf2-deficient mice with respect to naïve wild-type animals, although they did not reach statistical significance $(41582.0 \pm 3209.0$ and $19203.7 \pm 3898.1$ Units/g joint, $n=4$, respectively). The arthritic process slightly increased myeloperoxidase activity in wild-type animals (33781.3 \pm 6371.5 Units/g joint, $n=8$, with respect to naïve wild-type mice). Interestingly, arthritic Nrf2-deficient mice showed a dramatic increase with values of $88690.2 \pm 4838.6$ Units/g joint, $n=8, p<0.001$ with respect to naïve Nrf2-deficient mice and also to arthritic wild-type animals.

\section{$\mathrm{HO}-1$ and COX-2 protein expression in paw homogenates}

We studied the expression of HO-1, a target of Nrf2, in paw homogenates of day 10. As shown in Figures 6A and B, there is a low level of HO-1 in naïve animals and Nrf2 deficiency does not modify the constitutive expression of this protein. In arthritic animals, HO-1 protein was induced in both front paws and knees and this induction was decreased in $\mathrm{Nrf}^{-/-}$ mice. We also determined the expression of COX-2 in paw homogenates. Although no significant differences were observed between both groups of naïve animals, the induction of arthritis enhanced COX-2 expression in front paws and knees, and this expression was increased in $\mathrm{Nrf}^{-/-}$mice compared with wild-type animals, with statistical significance in front paws.

\section{Immunohistochemical analysis of iNOS expression in joint sections}

No significant iNOS positive cells were observed in naïve animals in joint sections of day 10. In contrast, iNOS was induced in the joint during the inflammatory process mainly in chondrocytes of ankles (Fig. 7A). In addition, iNOS induction 

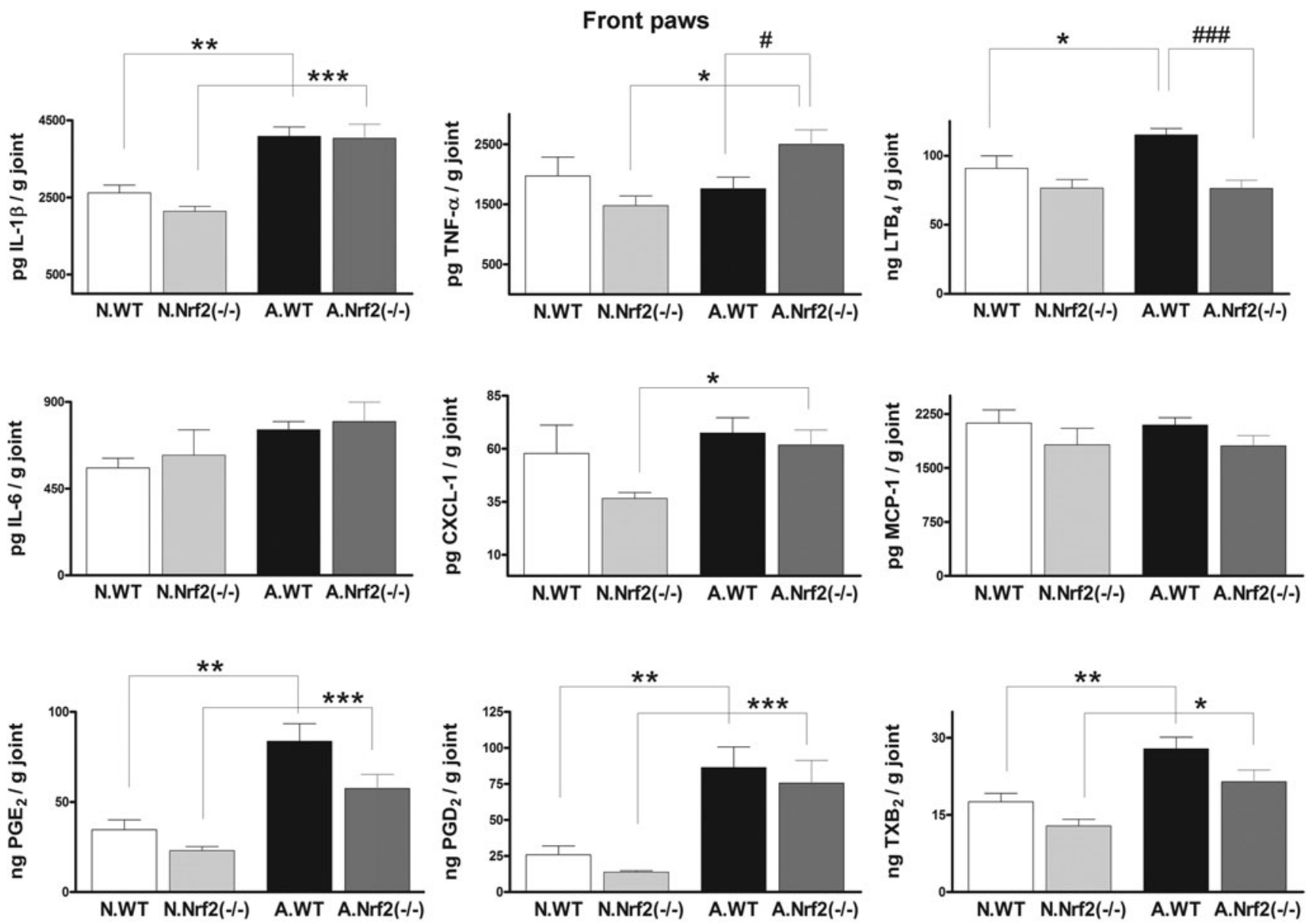

FIG. 5. Levels of inflammatory mediators in front paw homogenates on day 10. Data represent mean \pm S.E.M, $n=4-8$; ${ }^{* * *} p<0.001,{ }^{* *} p<0.01,{ }^{*} p<0.05$ each arthritic group compared with its respective naïve group, ${ }^{\# \#} p<0.001,{ }^{\#} p<0.05$ arthritic $\mathrm{Nrf2} 2^{-/-}$group with respect to arthritic wild-type group.

was significantly higher in front paws of arthritic $\mathrm{Nrf2}^{-/-}$mice with respect to arthritic wild-type animals (Fig. 7B).

\section{Immunohistochemical analysis of nitrotyrosine expression in joint sections}

Constitutive nitrotyrosine immunostaining was detected mainly in Nrf2-deficient mice in both ankles and front paw joints on day 10 (Figs. 8A and B), whereas the induction of arthritis increased nitrotyrosine expression that was apparent in chondrocytes, synovium, and infiltrate. We observed in arthritic animals that nitrotyrosine expression was enhanced in $\mathrm{Nrf}^{-/-}$mice compared to their wild-type counterparts with statistical significance in front paws.

\section{Discussion}

$\mathrm{K} / \mathrm{BxN}$ serum transfer to healthy mice leads to an autoimmune and inflammatory response mediated by IgG1 autoantibodies $(28,30)$. This animal model of arthritis exhibits clinical similarities to human rheumatoid arthritis, with cell infiltration, synovitis, pannus formation, and erosion of cartilage and bone (49). The $\mathrm{K} / \mathrm{BxN}$ serum transfer model emulates rheumatoid arthritis specificity as there is a jointspecific inflammation that may be dependent on autoantigen binding to cartilage surface (43). In this study, the induction of arthritis in naïve mice slightly increased neutrophil migration, an essential process to initiate and maintain arthritis (49), in front paws, but its effect in hind paws was strong. Of note, Nrf2 deficiency dramatically upregulated neutrophil migration in front paws. Therefore, maximal severity of arthritis was observed in hind paws of wild-type animals, limiting a further increase in inflammation in the presence of Nrf2 deficiency. In contrast, front paws exhibited a low-grade inflammation after induction of arthritis in wild-type animals that was significantly enhanced in $\mathrm{Nrf}^{-/-}$mice. Interestingly, our data have revealed that Nrf2 deficiency accelerates the incidence of arthritis in this experimental model and leads to a widespread disease, with important inflammation and lesions in both hind and front joints.

Induction of HO-1 during inflammatory conditions could be part of an adaptive mechanism to limit cytotoxicity via scavenging of reactive oxygen or nitrogen species, regulation of cell proliferation, and prevention of apoptosis (reviewed in (1)). We have shown previously that induction of HO-1 can exert partial anti-arthritic effects (9). In the present study, Nrf2 deficiency during $\mathrm{K} / \mathrm{BxN}$ serum transfer arthritis led to increased iNOS expression and production of reactive oxygen and nitrogen species, whereas the expression of $\mathrm{HO}-1$ was downregulated. Our results thus suggest that the increased production of oxidative stress due to Nrf2 deficiency may 
A

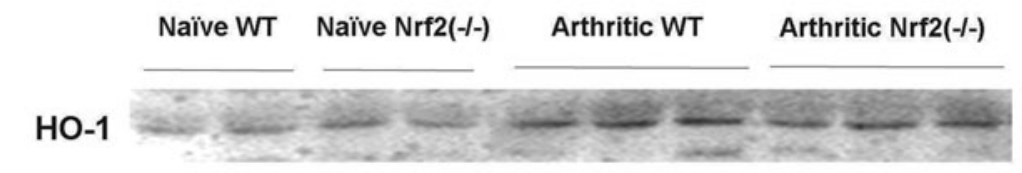

cox-2

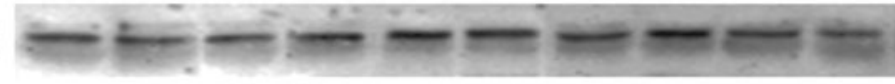

GAPDH

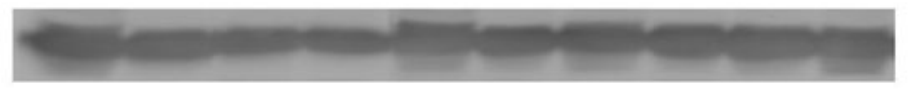

B

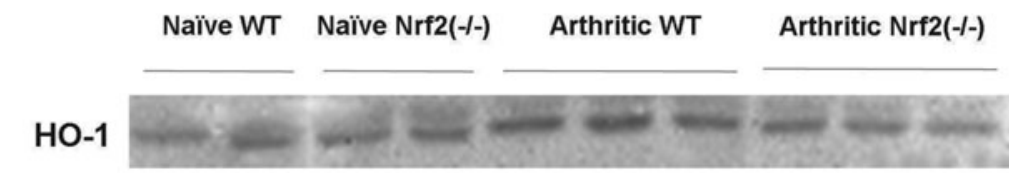

coX-2

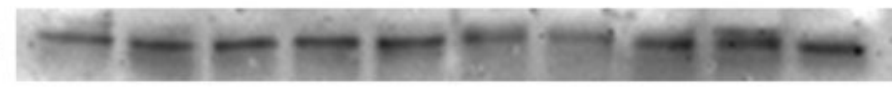

GAPDH

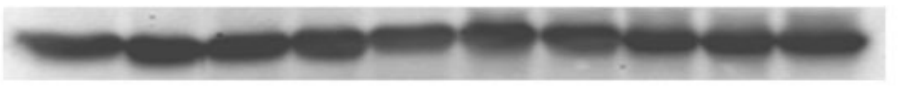

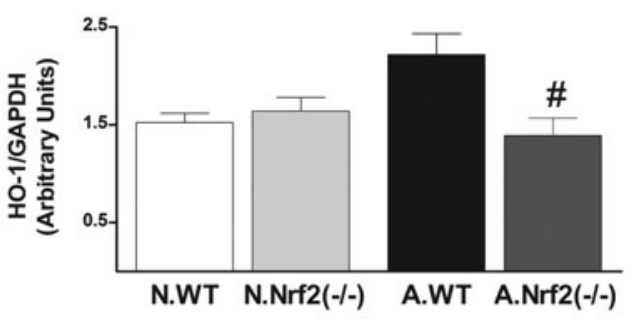
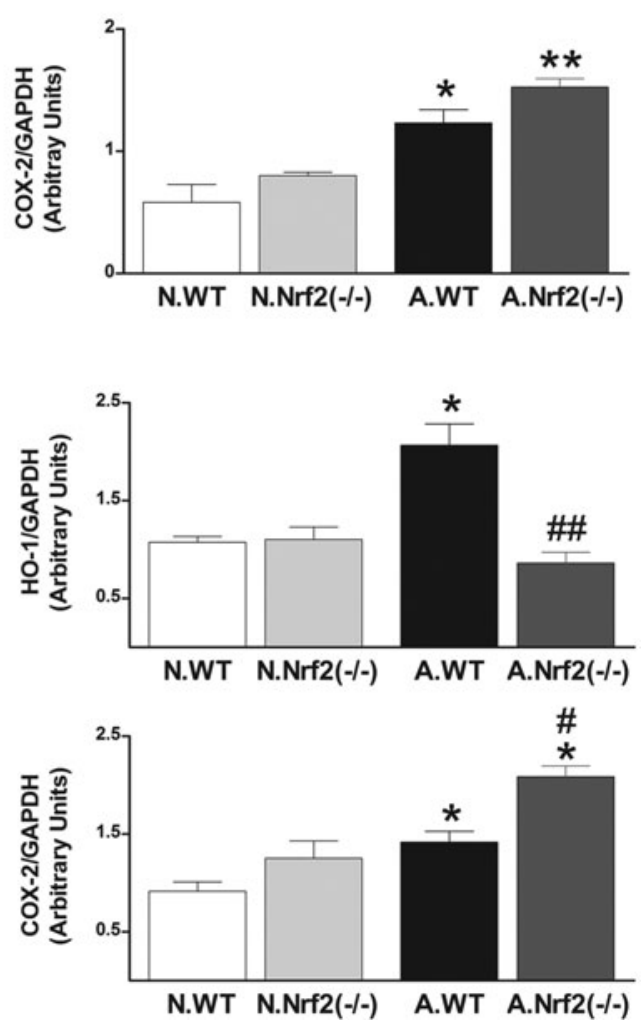

FIG. 6. Western blot analysis of HO-1 and COX-2 protein. (A) Hind paws (knees) homogenates; (B) front paws homogenates. GAPDH was used as a control. Relative expression of HO-1/COX-2 and GAPDH bands was calculated after densitometric analysis of samples. Data represent mean \pm S.E.M, $n=3 ;{ }^{* *} p<0.01,{ }^{*} p<0.05$ each arthritic group compared with its respective naïve group, ${ }^{\#} p<0.01,{ }^{\#} p<0.05$ arthritic $\mathrm{Nrf}^{-/-}$with respect to arthritic wild-type group.

mediate an enhanced inflammatory response and joint lesion in the $\mathrm{K} / \mathrm{BxN}$ serum transfer model of arthritis which is in line with data from anti-collagen II antibody-induced arthritis (50).

Increased eicosanoid production has been shown to contribute to the development of arthritis in human patients and animal models (5). There are differences in the eicosanoid profile according to the experimental model, as it has been reported a more relevant role for $\mathrm{COX}-1$ and $\mathrm{PGI}_{2}$ compared to COX-2 and $\mathrm{PGE}_{2}$ in the K/BxN serum transfer arthritis (5). In addition, our previous research suggests the participation of another prostanoid pathway, $\mathrm{PGD}_{2}$, in the effector phase of this arthritis model (29). Joint inflammation is dependent on neutrophil recruitment via $\mathrm{LTB}_{4}$ (6) which also stimulates synovial fibroblasts migration and invasion (7). In this study, the $\mathrm{PGI}_{2}$ metabolite 6-ketoPGF $\mathrm{PG}_{1 \alpha}, \mathrm{PGD}_{2}$, and $\mathrm{LTB}_{4}$ were significantly increased in the serum of arthritic wild-type mice on day 10, compared with naïve animals, whereas the small increase in $\mathrm{PGE}_{2}$ was not significant. The levels of these eicosanoids and $\mathrm{TXB}_{2}$ were also enhanced in the joints at that time point. In Nrf2 deficiency, the arthritic process significantly induced the production of eicosanoids, although the effect on $\mathrm{LTB}_{4}$ was weak and the production of serum 6-ketoPGF ${ }_{1 \alpha}$ and $\mathrm{LTB}_{4}$ in Nrf2-deficient mice was lower than in wild-type animals. These observations suggest the participation of $\mathrm{Nrf} 2$ in the modulation of eicosanoid synthesis and/or metabolism during inflammation. Little is known about the possible modification by this transcription factor of the expression or activity of enzymes involved in eicosanoid pathways. In our study, Nrf2 deficiency resulted in increased COX-2 expression in paws, which is in line with reports in ischemia-induced neovascularization (17). The regulation of enzymes involved in eicosanoid pathways is very complex in vivo. Although the Nrf2 enhancer element is present in thromboxane synthetase, different trans-activating factors may confer cell-type preferential expression (52). On the other hand, in situations of oxidative stress, $\mathrm{PGD}_{2}$ and cyclopentenone isoprostanes can be generated in a nonenzymatic manner (11) and therefore, this mechanism may contribute to the increased serum levels of this prostaglandin in arthritic $\mathrm{Nrf}^{-/-}$animals which have a reduced antioxidant defense system. Interestingly, our data indicate that Nrf2 deficiency results in a higher migration of 
A

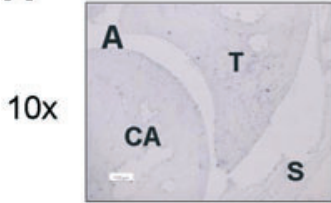

$20 x$

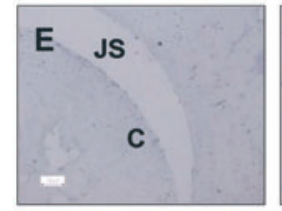

Neg

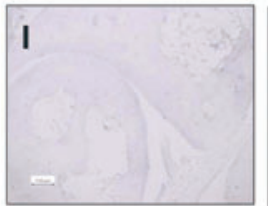

B

$20 x$

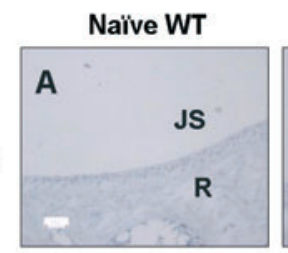

$40 x$

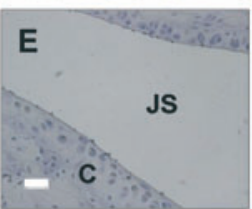

Neg

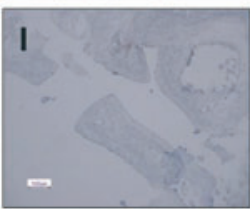

Naîve Nrf2 (-I-)
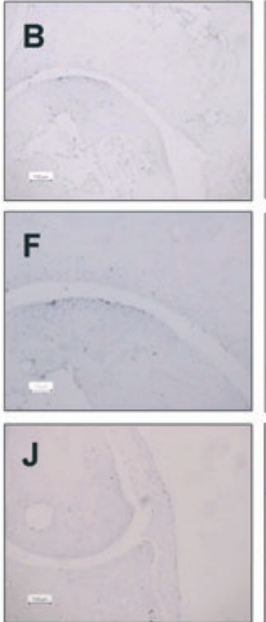

Naïve Nrf2 (-I-)
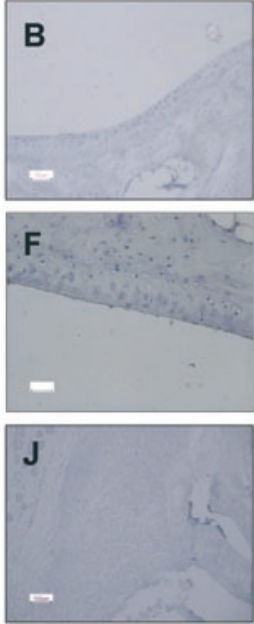

Arthritic WT
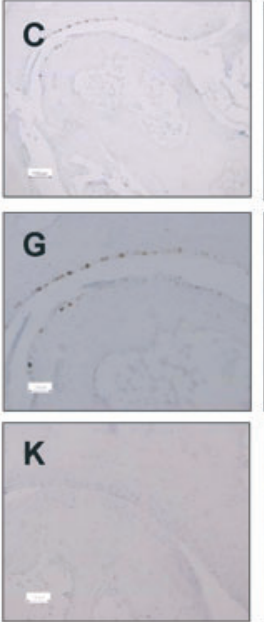

Arthritic WT
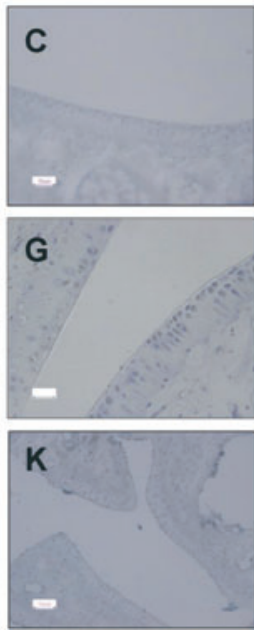

Arthritic Nrf2 (-/-)
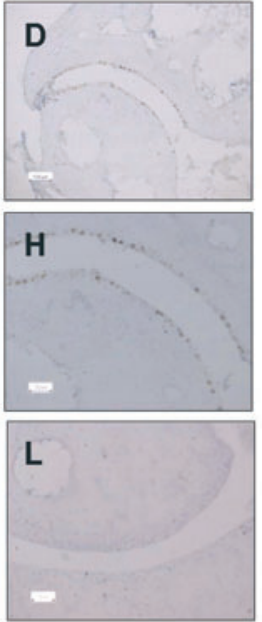

Arthritic Nrf2 (-I-)
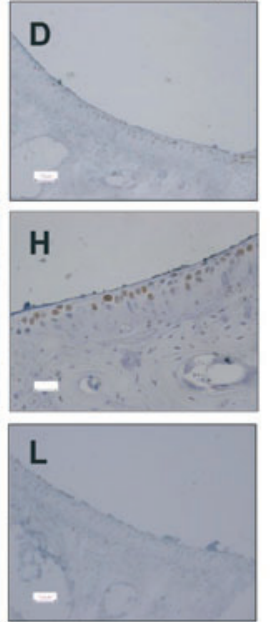

Hind paws (Ankles)
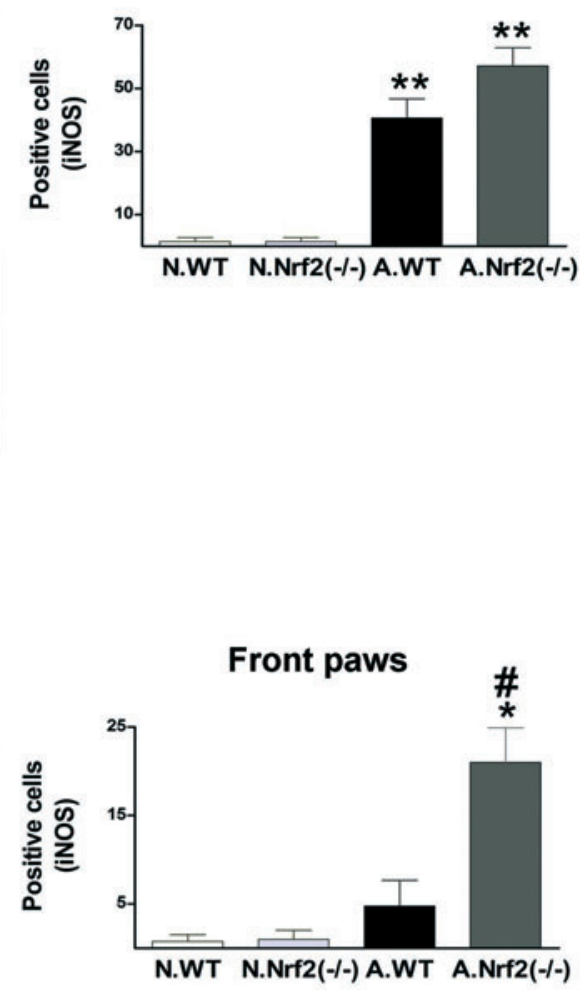

FIG. 7. Immunohistochemical analysis of iNOS in joints on day 10. (A) Ankle joint sections, (B) front joint sections. A, E, I, joint of naïve wild-type mouse; B, F, J, joint of naïve Nrf2 ${ }^{-/-}$mouse; C, G, K, joint of arthritic wild-type mouse; D, H, L, joint of arthritic Nrf2 $2^{-/-}$mouse. C, cartilage; CA, calcaneous; JS, joint space; S, synovium; T, tibia. A-H sections were treated with a specific anti-iNOS antibody whereas I-L sections were treated with rabbit IgG control. Original magnification X100 A (A-D). Original magnification X200 A (E-L), B (A-D, I-L). Original magnification X400 B $(\mathbf{E}-\mathbf{H})$. Data represent mean \pm S.E.M, $n=$ $4-8 ;{ }^{* *} p<0.01,{ }^{*} p<0.05$ each arthritic group compared with its respective naïve group, ${ }^{\#} p<0.05$ arthritic Nrf2 ${ }^{-/-}$group with respect to arthritic wild-type group. (To see this illustration in color, the reader is referred to the web version of this article at www.liebertonline.com/ars).

pro-inflammatory cells into the joints during the development of arthritis, which may be dependent on several inflammatory mediators.

Pro-inflammatory cytokines and chemokines play an important role in the effector phase of experimental arthritis. The arthritic process is associated with the increase of cytokines such as IL- $1 \beta$, TNF- $\alpha$, and IL-6, which are highly expressed in the joints of rheumatoid arthritis patients (10). In particular, experimental data support the view that TNF- $\alpha$ plays an important role in rheumatoid arthritis (48). Our results have shown an upregulation of cytokine expression during arthritis in Nrf2-deficient animals. Therefore, we observed significant differences in TNF- $\alpha$ and IL-6 levels with respect to wild-type animals. This is in line with recent reports indicating a higher infiltration of inflammatory cells into skeletal muscle and higher levels of TNF- $\alpha$ mRNA in Nrf2-deficient animals following ischemia (17). Similarly, pulmonary inflammation induced by lipopolysaccharide was enhanced in $\mathrm{Nrf2}^{-/-}$mice with increased mRNA expression of IL-6 in the lungs (25).

Pro-inflammatory cytokines inhibit bone formation and stimulate osteoblasts to produce RANKL leading to osteoclast activation and bone resorption (reviewed in (3)). In this study, the arthritic process resulted in enhanced serum levels of RANKL in the presence of Nrf2 deficiency whereas osteocalcin levels were significantly decreased. Therefore our data suggest that increased bone resorption and reduced bone formation contribute to arthritic changes in these animals and Nrf2 may be a protective factor for bone metabolism in the presence of inflammation.

It is known that oxidative stress can induce chemokine expression during inflammatory responses and thus activation of Nrf2 and induction of target genes such as HO-1 would inhibit chemokine production, as reported for IL-8 in HT-29 cells (26). Nevertheless, the role of Nrf2 may be more complex and in 
A
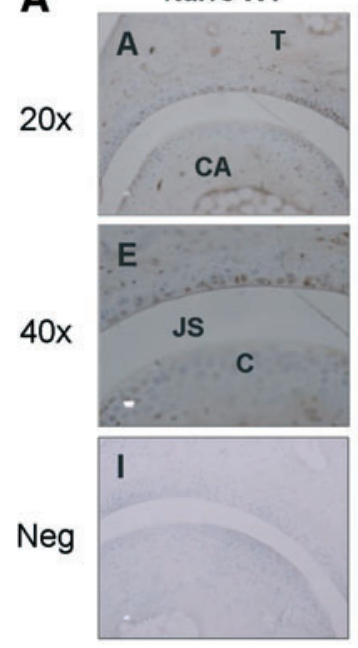

B

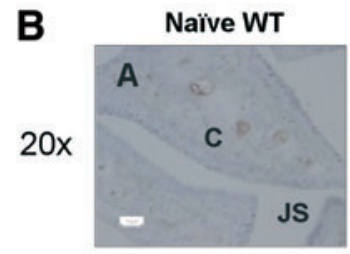

$40 x$

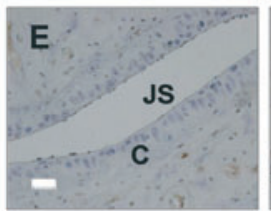

Neg

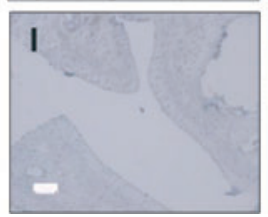

Naïve Nrf2 (-/-)
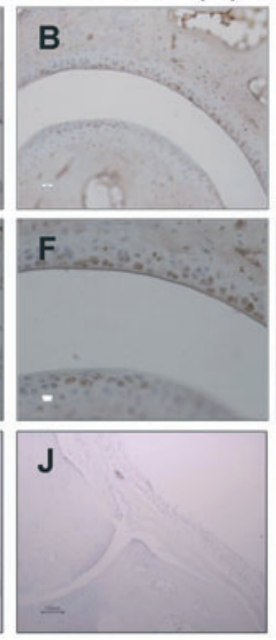

Naîve Nrf2 (-I-)
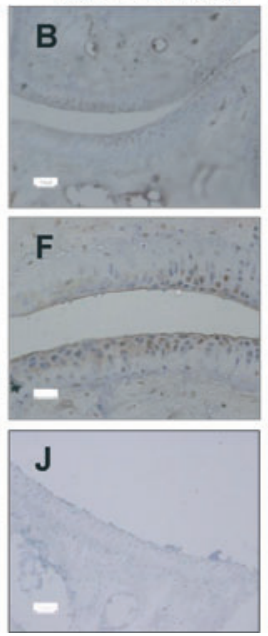

Arthritic WT
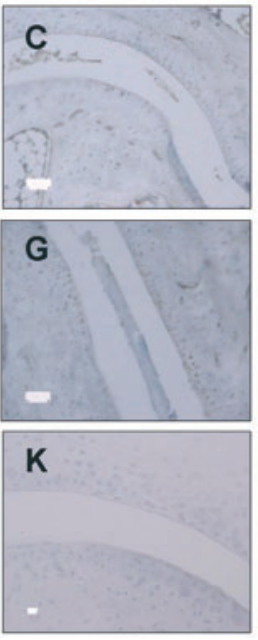

Arthritic WT
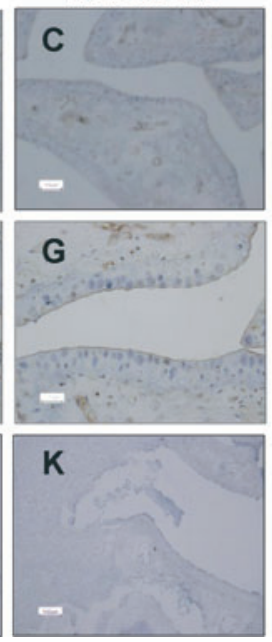

Arthritic Nrf2 (-/-)
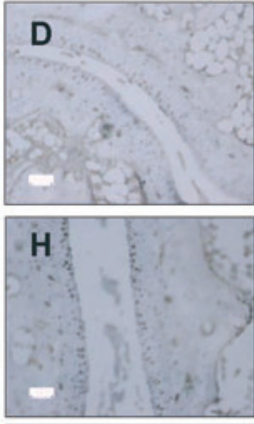

L

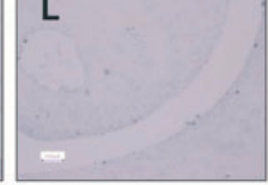

Arthritic Nrf2 (-/-)
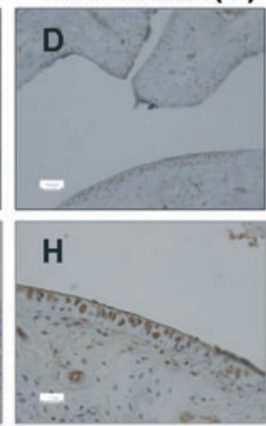

L
Hind paws (Ankles)
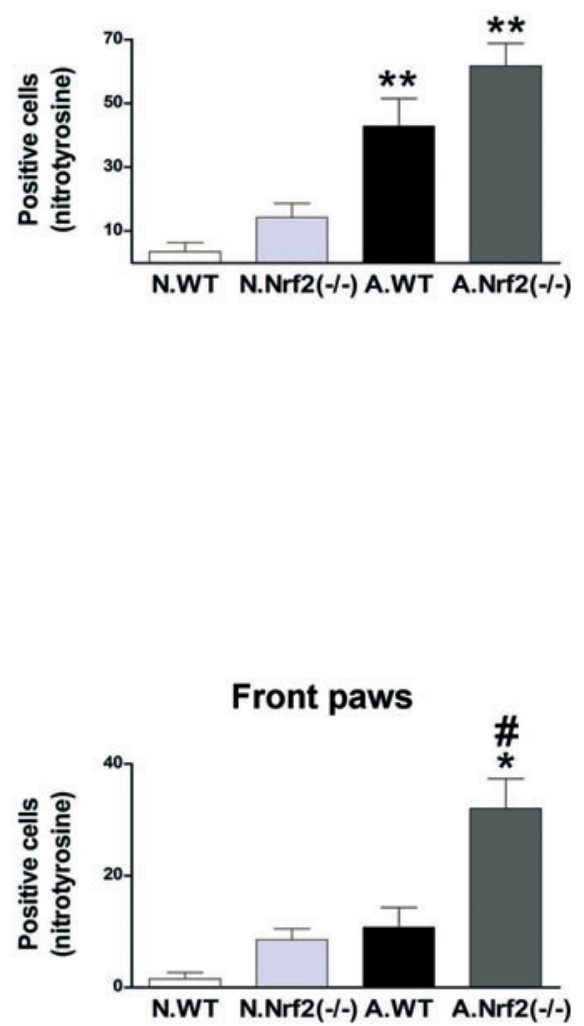

FIG. 8. Immunohistochemical analysis of nitrotyrosine in joints on day 10. (A) Ankle joint sections, (B) front joint sections. A, E, I, joint of naïve wild-type mouse; B, F, J, joint of naïve Nrf2 ${ }^{-/-}$mouse; C, G, K, joint of arthritic wild-type mouse; D, H, L, joint of arthritic Nrf2-/-mouse. C, cartilage; CA, calcaneous; JS, joint space; T, tibia. A-H sections were treated with a specific anti-nitrotyrosine antibody whereas I-L were treated with rabbit IgG control. Original magnification X200 (AD, I-L). Original magnification X400 (E-H). Data represent mean \pm S.E.M, $n=4-8 ;{ }^{* *} p<0.01,{ }^{*} p<0.05$ each arthritic group compared with its respective naïve group, ${ }^{\#} p<0.05$ arthritic $\mathrm{Nrf2}^{-/-}$group with respect to arthritic wild-type group. (To see this illustration in color, the reader is referred to the web version of this article at www.liebertonline.com/ars).

some cell types the activation of this transcription factor has been related to IL-8 mRNA stabilization (54). Chemokines are also upregulated in inflamed joints during $\mathrm{K} / \mathrm{BxN}$ serum transfer arthritis and could mediate neutrophil recruitment to the joints. Gene expression of CXCL1 is upregulated in ankles and synovial fluid in parallel with the progression of arthritis in this experimental model (20). This chemokine is a ligand of CXCR2 mediating the migration of different cell types during inflammatory conditions $(39,42)$. Recent studies have demonstrated that CXCR2 signaling is critical for $\mathrm{K} / \mathrm{BxN}$ serum transfer arthritis (20). It is interesting to note that CXCL-1 induction during the arthritic process is augmented by Nrf2 deficiency, which may play an important role in the potentiation of the inflammatory response observed in these animals.

MCP-1 is another inflammatory mediator upregulated during arthritis $(20,33)$. This chemokine enhances migration and proliferation of synovial fibroblasts as well as matrix metalloproteinase expression (12). Nevertheless, the influence of MCP-1 upregulation on arthritis progression is not clear, as recent studies using CCL2-deficient mice have shown no differences in disease severity with respect to wild-type animals in the K/BxN serum transfer model (20). Our data indicate that Nrf2 deficiency in arthritic animals results in the upregulation of MCP-1 in hind paws which is consistent with results in muscle ischemia and pulmonary inflammation (17, 25). It is known that MCP-1 promoter activation depends on nuclear factor $\kappa \mathrm{B}$ activity that responds to reactive oxygen species (51) and therefore increased oxidative stress in Nrf2 deficiency would facilitate MCP-1 synthesis.

In conclusion, our study provides novel insights into the role of Nrf2 in the inflammatory response in vivo. Taken together, our data suggest that Nrf2 acts upon the production of inflammatory mediators to modulate the systemic and local processes driving erosive arthritis. 


\section{Materials and Methods}

\section{Induction of arthritis}

$\mathrm{K} / \mathrm{BxN}$ mice were generated by crossing KRN-TCRtransgenic mice (B10.BR genetic background) with NOD mice. The C57BL/6J Nrf2 knockout mice were kindly provided by Dr. Masayuki Yamamoto (University of Tsukuba, Japan) (19). These mice exhibit a normal phenotype and lifespan, but are hypersensitive to treatments that lead to oxidative or inflammatory stress. For instance, these animals exhibit exacerbated neuron death, gliosis, and neuroinflammation after treatment with the parkinsonian toxin 1methyl-4-phenyl-1,2,3,6-tetrahydropyridine (40) or lipopolysaccharide (18).

Genotyping of wild-type $\left(\mathrm{Nrf} 2^{+/+}\right)$C57BL/6J mice and Nrf2-deficient ( $\mathrm{Nrf}^{-/-}$) littermates was done as reported previously (19). Arthritis was induced in 16-24-week-old mice by intraperitoneal injection of $150 \mu \mathrm{l}$ serum from arthritic $\mathrm{K} / \mathrm{BxN}$ mice on day 0 and 2. All mice were maintained in cages with a 12-hour light/dark cycle and free access to standard diet and water. Mice were housed and cared for by the veterinary staff in accredited facilities and were routinely screened for health status. Mice were assigned to their experimental group $(n=8$ in arthritic wild-type and arthritic $\mathrm{Nrf}^{-/-}$groups, $n=4$ in naïve wild-type and naïve $\mathrm{Nrf2}^{-/-}$ groups). Blood was collected from the retro-orbital venous plexus on day 10, and animals were then sacrificed by cervical dislocation. Hind and front paws from randomly selected animals in each group were isolated for histological and immunohistochemical analyses (8 ankles and 4 front paws in arthritic groups, 4 ankles and 4 front paws in naïve groups) and the rest of them were used for measurement of inflammatory markers. All studies were performed in accordance with European Union regulations for the handling and use of laboratory animals. The protocols were approved by the institutional Animal Care and Use Committees (University of Valencia and Autonomous University of Madrid, Spain).

\section{Arthritis score}

Joint inflammation was scored visually in each paw. The clinical severity of arthritis was graded using a scale of $0-2$ for each paw where $0=$ uninflamed, $1=$ mild, $1.5=$ marked, and 2 = severe inflammation. Scoring was performed by two independent observers without knowledge of the experimental groups.

\section{Measurement of inflammatory mediators in serum}

To determine the levels of prostaglandin(PG) $\mathrm{D}_{2}$ and 6ketoPGF ${ }_{1 \alpha}$ in serum samples, ELISA kits were used (Cayman Chemical, Ann Arbor, MI) with a range of detection of 78-10000 and 1.6-1000 pg/ml, respectively. PGE 2 and leukotriene $\mathrm{B}_{4}\left(\mathrm{LTB}_{4}\right)$ levels were measured by radioimmunoassay (32). CXCL-1 was determined by ELISA (Promokine, PromoCell GmbH, Heidelberg, Germany, 8$1000 \mathrm{pg} / \mathrm{ml}$ ). The levels of tumor necrosis factor $\alpha$ (TNF- $\alpha$ ), interleukin(IL)-6, osteocalcin, and receptor activator for nuclear factor $\kappa \mathrm{B}$ ligand (RANKL) in serum were determined by the LINCOplex ${ }^{\mathrm{TM}}$ system (Millipore Iberica, Madrid, Spain), with sensitivity of $0.8,0.6,7.0$, and $3.3 \mathrm{pg} / \mathrm{ml}$, respectively.

\section{Measurement of inflammatory mediators in paw homogenate}

Hind paws (knees) and front paws were amputated, homogenized in liquid $\mathrm{N}_{2}$ with $1 \mathrm{ml}$ of $\mathrm{A}$ buffer $\mathrm{pH}$ 7.46 $(10 \mathrm{mM}$ HEPES, pH 8, $1 \mathrm{mM}$ EDTA, $1 \mathrm{mM}$ EGTA, $10 \mathrm{mM} \mathrm{KCl}, 1 \mathrm{mM}$ dithiothreitol, $5 \mathrm{mM} \mathrm{NaF}, 1 \mathrm{mM} \mathrm{Na} \mathrm{VO}_{4}, 1 \mu \mathrm{g} / \mathrm{ml}$ leupeptin, $0.1 \mu \mathrm{g} / \mathrm{ml}$ aprotinine, and $0.5 \mathrm{mM}$ phenylmethyl sulfonyl fluoride). The tissue homogenates obtained were sonicated ( $10 \mathrm{sec}$ three times at $20 \%$ with a 10 -sec incubation on ice between bursts) in an ultrasonic processor (VC130PB, Sonics \& Materials Inc., Newtown, CT) and centrifuged at $1200 \mathrm{~g}$, $10 \mathrm{~min}$ at $4^{\circ} \mathrm{C}$. Supernatants were removed and used for determination of eicosanoid, cytokine, and chemokine levels. TNF- $\alpha$ and IL- $1 \beta$ were determined by ELISA (R\&D Systems Inc., Minneapolis, MN, with a range of detection of 32-2700 and $25-2000 \mathrm{pg} / \mathrm{ml}$, respectively). IL-6 and monocyte chemoattractant protein-1 (MCP-1) were measured using the ELISA kits from eBioscience Inc. (San Diego, CA), with sensitivity of 2 and $7 \mathrm{pg} / \mathrm{ml}$, respectively. CXCL- 1 and $\mathrm{PGD}_{2}$ were determined by ELISA, as indicated above, and $\mathrm{PGE}_{2}$, thromboxane $\mathrm{B}_{2}\left(\mathrm{TXB}_{2}\right)$ and $\mathrm{LTB}_{4}$ were quantified by radioimmunoassay (32). Myeloperoxidase activity was assayed as described previously (36).

\section{Histological analysis}

For standard histological assessment, isolated ankles and front paws were kept in $10 \%$ formalin for 4 days, decalcified in $5 \%$ formic acid, and subsequently dehydrated and embedded in paraffin. Standard frontal sections $(7 \mu \mathrm{m})$ of the joint tissue were mounted on SuperFrost slides (Menzel-Gläser, Braunschweig, Germany). Hematoxylin and eosin staining was performed to study joint inflammation. The severity of inflammation in the joints was scored on a scale of 0-3 $(0=$ no cells, $1=$ mild cellularity, $2=$ moderate cellularity, and $3=$ maximal cellularity). To study proteoglycan depletion from the cartilage matrix, sections were stained with safranin $\mathrm{O}$, followed by counterstaining with fast green. Depletion of proteoglycan was determined using an arbitrary scale of 0-3, ranging from normal, fully stained cartilage to destained cartilage that was fully depleted of proteoglycan. Bone destruction was graded on a scale of $0-3$, ranging from no damage to the complete loss of bone structure. Chondrocyte death was scored on a scale of $0-3$, where $0=$ no empty lacunae and $3=$ complete loss of chondrocytes from the cartilage layer. Cartilage surface erosion was scored on a scale of $0-3$, where $0=$ no cartilage loss and $3=$ complete loss of articular cartilage. Histopathologic changes were scored on three semiserial sections of the joint, with sections spaced $70 \mu \mathrm{m}$ apart. Scoring was performed in a blind manner by two independent observers.

\section{Immunohistochemistry}

For immunohistochemical analyses, isolated ankles and front paws were fixed for 4 days in $10 \%$ formalin, decalcified in EDTA (10\%), and subsequently dehydrated and embedded in paraffin. Tissue sections $(7 \mu \mathrm{m})$ were deparaffinized, rehydrated, and treated with $2 \% \mathrm{H}_{2} \mathrm{O}_{2}$ for $10 \mathrm{~min}$ at room temperature. Sections were incubated for $15 \mathrm{~min}$ with goat antiserum (1:10), and thereafter incubated for $2 \mathrm{~h}$ with rabbit anti-mouse antibodies against inducible nitric oxide synthase 
(iNOS) or nitrotyrosine (22036a and 10189540, respectively; Cayman Chemical). Rabbit IgG antibody (Dako, Glostrup, Denmark) was used as control. After rinsing, sections were incubated for $30 \mathrm{~min}$ with the secondary biotinylated antibody: swine anti-rabbit antibody (Dako), and processed using streptavidin-horseradish peroxidase (Dako). Development of the peroxidase staining was performed with diaminobenzidine (Sigma-Aldrich, St Louis, MO). Sections were counterstained with hematoxylin for $1 \mathrm{~min}$. Positive cells were evaluated in the joint cartilage (tibia-calcaneous in two semiserial sections of the ankle and radius in two semiserial sections of the front paw) by two independent observers.

\section{Western blot analysis}

Supernatants from paw homogenates (knees and front paws) were sonicated (10 sec twice at $20 \%$ with a 10 -sec incubation on ice between bursts) in an ultrasonic processor (VC130PB, Sonics \& Materials Inc.) and centrifuged at 10,000 g for $15 \mathrm{~min}$ at $4^{\circ} \mathrm{C}$. The new supernatants were used to assess heme oxygenase-1 (HO-1) and cyclooxygenase (COX)-2 protein expression. Equal amounts of protein were loaded on $10 \%$ SDS-PAGE and transferred onto polyvinylidene difluoride Hybond-P membranes (GE Healthcare, Barcelona, Spain) for $120 \mathrm{~min}$ at $125 \mathrm{~mA}$. Membranes were blocked in phosphatebuffered saline (0.02 M, pH 7.0)-Tween 20 (0.1\%) containing $4 \% \mathrm{w} / \mathrm{v}$ unfatted milk, and incubated with a specific polyclonal antibody against HO-1 (1/1000) (SPA-896, Stressgen, Victoria, British Columbia, Canada), COX-2 (1/1000) (160116, Cayman Chemical) or glyceraldehyde 3-phosphate dehydrogenase (GAPDH, 1/10000) (G9545, Sigma-Aldrich). Finally, blots were washed and membranes were incubated with peroxidase-conjugated goat anti-rabbit IgG (1/5000, Dako). The immunoreactive bands were visualized using an enhanced chemiluminescence system $\left(\mathrm{ECL}^{\mathrm{TM}}\right.$ Western Blotting Detection reagents, GE Healthcare). Images were captured with the AutoChemi image analyzer (UVP Inc., Upland, CA) and protein band densitometry was performed.

\section{Statistical analysis}

Differences between experimental groups were tested using the two-tailed Mann-Whitney $U$ test. $P$ values less than 0.05 were considered significant

\section{Acknowledgments}

This study was supported by Grants SAF2010-22048, SAF2010-1788, and RETICEF RD06/0013/2001 (Ministerio de Ciencia e Innovación, ISCIII, FEDER), and Prometeo2010047 (Generalitat Valenciana).

\section{Author Disclosure Statement}

The authors declare no competing financial interests

\section{References}

1. Alcaraz MJ, Fernandez P, and Guillen MI. Anti-inflammatory actions of the heme oxygenase-1 pathway. Curr Pharm Des 9: 2541-2551, 2003.

2. Becks L, Prince M, Burson H, Christophe C, Broadway M, Itoh K, Yamamoto M, Mathis M, Orchard E, Shi R, McLarty J, Pruitt K, Zhang S, and Kleiner-Hancock HE. Aggressive mammary carcinoma progression in Nrf2 knockout mice treated with 7,12-dimethylbenz[a]anthracene. BMC Cancer 10: 540, 2010.

3. Bezerra MC, Carvalho JF, Prokopowitsch AS, and Pereira RM. RANK, RANKL and osteoprotegerin in arthritic bone loss. Braz J Med Biol Res 38: 161-170, 2005.

4. Chan K, Lu R, Chang JC, and Kan YW. NRF2, a member of the NFE2 family of transcription factors, is not essential for murine erythropoiesis, growth, and development. Proc Natl Acad Sci USA 93: 13943-13948, 1996.

5. Chen M, Boilard E, Nigrovic PA, Clark P, Xu D, FitzGerald GA, Audoly LP, and Lee DM. Predominance of cyclooxygenase 1 over cyclooxygenase 2 in the generation of proinflammatory prostaglandins in autoantibody-driven $\mathrm{K} / \mathrm{BxN}$ serum-transfer arthritis. Arthritis Rheum 58: 1354-1365, 2008.

6. Chen M, Lam BK, Kanaoka Y, Nigrovic PA, Audoly LP, Austen KF, and Lee DM. Neutrophil-derived leukotriene B4 is required for inflammatory arthritis. J Exp Med 203: 837842, 2006.

7. Chen M, Lam BK, Luster AD, Zarini S, Murphy RC, Bair AM, Soberman RJ, and Lee DM. Joint tissues amplify inflammation and alter their invasive behavior via leukotriene B4 in experimental inflammatory arthritis. J Immunol 185: 5503-5511, 2010.

8. Cho HY, Reddy SP, Yamamoto M, and Kleeberger SR. The transcription factor NRF2 protects against pulmonary fibrosis. FASEB J 18: 1258-1260, 2004.

9. Devesa I, Ferrandiz ML, Terencio MC, Joosten LA, van den Berg WB, and Alcaraz MJ. Influence of heme oxygenase 1 modulation on the progression of murine collagen-induced arthritis. Arthritis Rheum 52: 3230-3238, 2005.

10. Feldmann M and Maini RN. The role of cytokines in the pathogenesis of rheumatoid arthritis. Rheumatology (Oxford) 38 Suppl 2: 3-7, 1999.

11. Gao L, Zackert WE, Hasford JJ, Danekis ME, Milne GL, Remmert C, Reese J, Yin H, Tai HH, Dey SK, Porter NA, and Morrow JD. Formation of prostaglandin E2 and prostaglandin D2 via the isoprostane pathway: A mechanism for the generation of bioactive prostaglandins independent of the cyclooxygenase. J Biol Chem 278: 28479-28489, 2003.

12. Garcia-Vicuna R, Gomez-Gaviro MV, Dominguez-Luis MJ, Pec MK, Gonzalez-Alvaro I, Alvaro-Gracia JM, and DiazGonzalez F. CC and CXC chemokine receptors mediate migration, proliferation, and matrix metalloproteinase production by fibroblast-like synoviocytes from rheumatoid arthritis patients. Arthritis Rheum 50: 3866-3877, 2004.

13. Healy ZR, Lee NH, Gao X, Goldring MB, Talalay P, Kensler TW, and Konstantopoulos K. Divergent responses of chondrocytes and endothelial cells to shear stress: Cross-talk among COX-2, the phase 2 response, and apoptosis. Proc Natl Acad Sci USA 102: 14010-14015, 2005.

14. Hinoi E, Fujimori S, Wang L, Hojo H, Uno K, and Yoneda Y. Nrf2 negatively regulates osteoblast differentiation via interfering with Runx2-dependent transcriptional activation. J Biol Chem 281: 18015-18024, 2006.

15. Hinoi E, Takarada T, Fujimori S, Wang L, Iemata M, Uno K, and Yoneda Y. Nuclear factor E2 p45-related factor 2 negatively regulates chondrogenesis. Bone 40: 337-344, 2007.

16. Huang J, Tabbi-Anneni I, Gunda V, and Wang L. Transcription factor Nrf2 regulates SHP and lipogenic gene expression in hepatic lipid metabolism. Am J Physiol Gastrointest Liver Physiol 299: G1211-1221, 2010.

17. Ichihara S, Yamada Y, Liu F, Murohara T, Itoh K, Yamamoto $\mathrm{M}$, and Ichihara G. Ablation of the transcription factor Nrf2 
promotes ischemia-induced neovascularization by enhancing the inflammatory response. Arterioscler Thromb Vasc Biol 30: 1553-1561, 2010.

18. Innamorato NG, Rojo AI, Garcia-Yague AJ, Yamamoto M, de Ceballos ML, and Cuadrado A. The transcription factor Nrf2 is a therapeutic target against brain inflammation. $J$ Immunol 181: 680-689, 2008.

19. Itoh $\mathrm{K}$, Chiba $\mathrm{T}$, Takahashi $\mathrm{S}$, Ishii $\mathrm{T}$, Igarashi $\mathrm{K}$, Katoh $\mathrm{Y}$, Oyake T, Hayashi N, Satoh K, Hatayama I, Yamamoto M, and Nabeshima Y. An Nrf2/small Maf heterodimer mediates the induction of phase II detoxifying enzyme genes through antioxidant response elements. Biochem Biophys Res Commun 236: 313-322, 1997.

20. Jacobs JP, Ortiz-Lopez A, Campbell JJ, Gerard CJ, Mathis D, and Benoist C. Deficiency of CXCR2, but not other chemokine receptors, attenuates autoantibody-mediated arthritis in a murine model. Arthritis Rheum 62: 1921-1932, 2010.

21. Jin $W$, Wang $H$, Yan $W$, Xu L, Wang $X$, Zhao X, Yang $X$, Chen G, and Ji Y. Disruption of Nrf2 enhances upregulation of nuclear factor-kappaB activity, proinflammatory cytokines, and intercellular adhesion molecule- 1 in the brain after traumatic brain injury. Mediators Inflamm 2008: 725174, 2008.

22. Kataoka $\mathrm{K}$, Handa $\mathrm{H}$, and Nishizawa M. Induction of cellular antioxidative stress genes through heterodimeric transcription factor Nrf2/small Maf by antirheumatic gold(I) compounds. J Biol Chem 276: 34074-34081, 2001.

23. Khor TO, Huang MT, Kwon KH, Chan JY, Reddy BS, and Kong AN. Nrf2-deficient mice have an increased susceptibility to dextran sulfate sodium-induced colitis. Cancer Res 66: 11580-11584, 2006.

24. Kim J, Cha YN, and Surh YJ. A protective role of nuclear erythroid 2-related factor-2 (Nrf2) in inflammatory disorders. Mutat Res 690: 12-23, 2010.

25. Kong $X$, Thimmulappa R, Kombairaju P, and Biswal S. NADPH oxidase-dependent reactive oxygen species mediate amplified TLR4 signaling and sepsis-induced mortality in Nrf2-deficient mice. J Immunol 185: 569-577, 2010.

26. Lee SH, Sohn DH, Jin XY, Kim SW, Choi SC, and Seo GS. $2^{\prime}, 4^{\prime}, 6^{\prime}$-tris(methoxymethoxy) chalcone protects against trinitrobenzene sulfonic acid-induced colitis and blocks tumor necrosis factor-alpha-induced intestinal epithelial inflammation via heme oxygenase 1-dependent and independent pathways. Biochem Pharmacol 74: 870-880, 2007.

27. Ma Q, Battelli L, and Hubbs AF. Multiorgan autoimmune inflammation, enhanced lymphoproliferation, and impaired homeostasis of reactive oxygen species in mice lacking the antioxidant-activated transcription factor Nrf2. Am J Pathol 168: 1960-1974, 2006.

28. Maccioni M, Zeder-Lutz G, Huang H, Ebel C, Gerber P, Hergueux J, Marchal P, Duchatelle V, Degott C, van Regenmortel M, Benoist C, and Mathis D. Arthritogenic monoclonal antibodies from K/BxN mice. J Exp Med 195: 1071-1077, 2002.

29. Maicas N., Ferrandiz ML, Devesa I, Motterlini R, Koenders MI, van den Berg WB, and Alcaraz MJ. The CO-releasing molecule CORM-3 protects against articular degradation in the K/BxN serum transfer arthritis model. Eur J Pharmacol 634, 184-191, 2010.

30. Matsumoto I, Maccioni M, Lee DM, Maurice M, Simmons B, Brenner M, Mathis D, and Benoist C. How antibodies to a ubiquitous cytoplasmic enzyme may provoke joint-specific autoimmune disease. Nat Immunol 3: 360-365, 2002.

31. Moi P, Chan K, Asunis I, Cao A, and Kan YW. Isolation of NF-E2-related factor 2 (Nrf2), a NF-E2-like basic leucine zipper transcriptional activator that binds to the tandem NFE2/AP1 repeat of the beta-globin locus control region. Proc Natl Acad Sci USA 91: 9926-9930, 1994.

32. Moroney MA, Alcaraz MJ, Forder RA, Carey F, and Hoult JRS. Selectivity of neutrophil 5-lipoxygenase and cyclooxygenase inhibition by an anti-inflammatory flavonoid glycoside and related aglycone flavonoids. I Pharm Pharmacol 40: 787-792, 1988.

33. Ogata H, Takeya M, Yoshimura T, Takagi $\mathrm{K}$, and Takahashi $\mathrm{K}$. The role of monocyte chemoattractant protein-1 (MCP-1) in the pathogenesis of collagen-induced arthritis in rats. $J$ Pathol 182: 106-114, 1997.

34. Osburn WO and Kensler TW. Nrf2 signaling: An adaptive response pathway for protection against environmental toxic insults. Mutat Res 659: 31-39, 2008.

35. Park SY, Lee SW, Shin HK, Chung WT, Lee WS, Rhim BY, Hong KW, and Kim CD. Cilostazol enhances apoptosis of synovial cells from rheumatoid arthritis patients with inhibition of cytokine formation via Nrf2-linked heme oxygenase 1 induction. Arthritis Rheum 62: 732-741, 2010.

36. Payá M, Terencio MC, Ferrándiz ML, and Alcaraz MJ. Involvement of secretory phospholipase $\mathrm{A}_{2}$ activity in the zymosan rat air pouch model of inflammation. $\mathrm{Br} J$ Pharmacol 117: 1773-1779, 1996.

37. Pi J, Leung L, Xue P, Wang W, Hou Y, Liu D, YehudaShnaidman E, Lee C, Lau J, Kurtz TW, and Chan JY. Deficiency in the nuclear factor E2-related factor-2 transcription factor results in impaired adipogenesis and protects against diet-induced obesity. J Biol Chem 285: 9292-9300, 2010.

38. Rangasamy T, Guo J, Mitzner WA, Roman J, Singh A, Fryer AD, Yamamoto M, Kensler TW, Tuder RM, Georas SN, and Biswal S. Disruption of Nrf2 enhances susceptibility to severe airway inflammation and asthma in mice. J Exp Med 202: 47-59, 2005.

39. Reutershan J, Morris MA, Burcin TL, Smith DF, Chang D, Saprito MS, and Ley K. Critical role of endothelial CXCR2 in LPS-induced neutrophil migration into the lung. J Clin Invest 116: 695-702, 2006.

40. Rojo AI, Innamorato NG, Martin-Moreno AM, de Ceballos ML, Yamamoto M, and Cuadrado A. Nrf2 regulates microglial dynamics and neuroinflammation in experimental Parkinson's disease. GLIA 58: 588-598, 2010.

41. Satoh H, Moriguchi T, Taguchi K, Takai J, Maher JM, Suzuki T, Winnard PT, Raman V, Ebina M, Nukiwa T, and Yamamoto M. Nrf2-deficiency creates a responsive microenvironment for metastasis to the lung. Carcinogenesis 31: 1833-1843, 2010.

42. Shahrara S, Pickens SR, Mandelin AM, Karpus WJ, Huang Q, Kolls JK, and Pope RM. IL-17-mediated monocyte migration occurs partially through CC chemokine ligand 2/ monocyte chemoattractant protein-1 induction. J Immunol 184: 4479-4487, 2010.

43. Studelska DR, Mandik-Nayak L, Zhou X, Pan J, Weiser P, McDowell LM, Lu H, Liapis H, Allen PM, Shih FF, and Zhang L. High affinity glycosaminoglycan and autoantigen interaction explains joint specificity in a mouse model of rheumatoid arthritis. J Biol Chem 284: 2354-2362, 2009.

44. Sussan TE, Jun J, Thimmulappa R, Bedja D, Antero M, Gabrielson KL, Polotsky VY, and Biswal S. Disruption of Nrf2, a key inducer of antioxidant defenses, attenuates ApoE-mediated atherosclerosis in mice. PLoS ONE 3: e3791, 2008.

45. Thimmulappa RK, Lee H, Rangasamy T, Reddy SP, Yamamoto M, Kensler TW, and Biswal S. Nrf2 is a critical regu- 
lator of the innate immune response and survival during experimental sepsis. J Clin Invest 116: 984-995, 2006.

46. van Wietmarschen $\mathrm{H}$, Yuan $\mathrm{K}$, Lu C, Gao P, Wang J, Xiao C, Yan X, Wang M, Schroen J, Lu A, Xu G, and van der Greef J. Systems biology guided by Chinese medicine reveals new markers for sub-typing rheumatoid arthritis patients. J Clin Rheumatol 15: 330-337, 2009.

47. Williams MA, Rangasamy T, Bauer SM, Killedar S, Karp M, Kensler TW, Yamamoto M, Breysse P, Biswal S, and Georas $\mathrm{SN}$. Disruption of the transcription factor Nrf2 promotes pro-oxidative dendritic cells that stimulate Th2-like immunoresponsiveness upon activation by ambient particulate matter. J Immunol 181: 4545-4559, 2008.

48. Williams RO, Inglis JJ, Simelyte E, Criado G, and Sumariwalla PF. Analysing the effect of novel therapies on cytokine expression in experimental arthritis. Int J Exp Pathol 86: 267-278, 2005.

49. Wipke BT and Allen PM. Essential role of neutrophils in the initiation and progression of a murine model of rheumatoid arthritis. J Immunol 167: 1601-1608, 2001.

50. Wruck CJ, Fragoulis A, Gurzynski A, Brandenburg LO, Kan YW, Chan K, Hassenpflug J, Freitag-Wolf S, Varoga D, Lippross S, and Pufe T. Role of oxidative stress in rheumatoid arthritis: insights from the Nrf2-knockout mice. Ann Rheum Dis 70: 844-850, 2011.

51. Xing L and Remick DG. Promoter elements responsible for antioxidant regulation of MCP-1 gene expression. Antioxid Redox Signal 9: 1979-1989, 2007.

52. Yaekashiwa M and Wang LH. Nrf2 regulates thromboxane synthase gene expression in human lung cells. DNA Cell Biol 22: 479-487, 2003.

53. Zhang DD. The Nrf2-Keap1-ARE signaling pathway: The regulation and dual function of Nrf2 in cancer. Antioxid Redox Signal 13: 1623-1626, 2010.
54. Zhang $X$, Chen $X$, Song H, Chen HZ, and Rovin BH. Activation of the Nrf2/antioxidant response pathway increases IL-8 expression. Eur J Immunol 35: 3258-3267, 2005.

Address correspondence to: Prof. Maria J. Alcaraz

Department of Pharmacology University of Valencia

Avda. Vicent Andrés Estellés s/n 46100 Burjassot

Valencia Spain

E-mail: maria.j.alcaraz@uv.es

Date of first submission to ARS Central, December 10, 2010; date of final revised submission, March 14, 2011; date of acceptance, March 15, 2011.

$\begin{aligned} & \quad \text { Abbreviations Used } \\ & \mathrm{COX}=\text { cyclooxygenase } \\ & \mathrm{GAPDH}=\text { glyceraldehyde } 3 \text {-phosphate dehydrogenase } \\ & \mathrm{HO}-1=\text { heme oxygenase- } 1 \\ & \mathrm{IL}=\text { interleukin } \\ & \mathrm{iNOS}=\text { inducible nitric oxide synthase } \\ & \mathrm{LTB}=\text { leukotriene } \mathrm{B}_{4} \\ & \mathrm{MCP}-1=\text { monocyte chemoattractant protein }-1 \\ & \mathrm{Nrf} 2=\text { NF- } \text { E }_{2} \text {-related factor } 2 \\ & \mathrm{PG}=\text { prostaglandin } \\ & \mathrm{RANKL}=\text { receptor activator of nuclear factor } \kappa \mathrm{B} \text { ligand } \\ & \mathrm{TNF} \alpha=\text { tumor necrosis factor- } \alpha \\ & \mathrm{TXB}=\text { thromboxane } \mathrm{B}_{2}\end{aligned}$


